\title{
O discurso psicanalítico entre outros: considerações sobre Radiofonia
}

\section{The psychoanalytic discourse among others: considerations about Radiophony}

\author{
Fábio Santos Bispo* \\ Universidade Federal de Minas Gerais - UFMG, Belo Horizonte, Minas Gerais, Brasil \\ Marcelo Fonseca Gomes de Souza** \\ Universidade Federal de Minas Gerais - UFMG, Belo Horizonte, Minas Gerais, Brasil
}

\begin{abstract}
RESUMO
O objetivo deste artigo é fazer um comentário que esclareça os argumentos propostos por Lacan no texto Radiofonia. Empreendemos uma leitura crítica de cada questão proposta a Lacan na entrevista relatada nesse texto, buscando esclarecer pontos complexos de sua resposta e circunscrever possíveis linhas de leitura. Ao situar o discurso da psicanálise entre outros, como o da linguística, da antropologia e da filosofia, Lacan destaca, além da especificidade epistemológica, a dimensão de ruptura e de subversão que a noção de inconsciente engendra. Ao formalizar o modo de funcionamento dos diversos discursos a partir do esquema dos quatro discursos, Lacan nos oferece uma ferramenta que esclarece de forma ainda mais contundente o modo de operação do discurso psicanalítico.
\end{abstract}

Palavras-chave: Radiofonia, Inconsciente, Discurso da psicanálise.

\begin{abstract}
The aim of this article is to clarify the arguments proposed by Lacan in the text Radiophony. We undertake a critical reading of each question addressed to Lacan in the interview reported in this text, in search to clarify the complex points of his replies and delimit the possible lines of reading. By situating the psychoanalytic discourse among others, such as linguistics, anthropology and philosophy, Lacan points out, beyond the epistemological specificity, the aspect of disruption and subversion that engenders the notion of the unconscious. Formalizing the operational mode of the several speeches from the schema of the four discourses, Lacan offers us an instrument that clarifies even more striking the mode of operation of the psychoanalytic discourse.
\end{abstract}

Key-words: Radiophony, Unconscious, Discourse of psychoanalysis. 


\section{I ntrodução}

Apresentar o comentário de um texto de Lacan não é tarefa fácil. Ainda que sua argumentação gire em torno de um tema escolhido preliminarmente, os circunlóquios realizados, seja durante a oralidade de seus seminários, seja no encadeamento reflexivo de seus escritos, costumam deixar o leitor numa suspensão interpretativa em relação aos sentidos que lhes podem ser atribuídos.

A leitura de Radiofonia cria um desconforto adicional que é, no mínimo, provocador. Como foi - perguntamo-nos depois de percorrer minuciosamente o texto - que os rádio-espectadores escutaram aquilo que Lacan tinha para dizer sobre as perguntas que lhe foram dirigidas? Sem o auxílio do texto escrito e sem a presença visual do psicanalista com toda sua conhecida expressividade, aquele que pacientemente escuta Lacan pelas ondas curtas precisa contentar-se com o abismo que a falta de um centro fixo lança aos ouvidos. Na verdade, é pelo deslocamento em relação a um movimento perfeito com tudo que isso remete à física ptolomaica e que, como leitores, esperamos de um bom autor - que Lacan faz assentar a sua fala. Ela é aí, num movimento marcado de intencionalidade, uma escrita elíptica, ou seja, feita para dar suporte ao centro vazio que determina a própria prática a que ela se aplica: a psicanálise. Lacan (1970/2003) mesmo diz, numa clara via de justificação:

Digo estas coisas difíceis por saber que a inaptidão de meus ouvintes os coloca em pé de igualdade com elas. Que o vício do psicanalista de ser, por seu ato, pessoa mais deslocada do que qualquer outra, torna-o inapto de uma outra maneira, isso é o que faz com que cada um de meus Escritos seja tão cheio de circunlóquios, constituindo barragem a que ele se sirva deles ao seu bel-prazer (LACAN, 1970 2003, p. 417).

Não é, pois, sem intenção que Lacan evita buscar uma fácil compreensão daquilo de que ele trata. A tensão, índice de desprazer, que marca a leitura de um texto como Radiofonia, merece uma interpretação. Talvez seja resultado da apresentação imperfeita daquilo que não se pode apresentar com perfeição. A estratégia de Lacan consiste em lançar-nos no caráter parcial do saber diante da impossibilidade de toda-verdade, do sentido do todo, que, por um quiasma, seria um todo-de-sentido.

Felizmente, entretanto, temos, impresso para a manipulação, o que foi dito na rádio. Pois, ainda que seja justificada a alternativa lacaniana de brincar com o aborrecimento de seu ouvinte, não é possível amar o abismo onde o real nos lança. Rapidamente torna-se necessário cerzir, em torno do vazio de sentido, pontos de ancoragem da significação, comunicando esse exercício àqueles que querem aderir à nossa práxis. É esse o motivo de empreendermos este 
trabalho, pois tal transmissão não pode ser verdadeiramente realizável sem que a circunscrevamos e a formalizemos. Somos, portanto, sempre convidados a um repto: aceitar a falta, mas desafiá-la (ininterruptamente!).

\section{Um discurso entre outros}

Optaremos, na apresentação do texto, por seguir a ordem estipulada pelo entrevistador. Atendo-nos a cada resposta dada, tentaremos esclarecer alguns argumentos fornecidos pelo autor.

1- "Nos Escritos, o senhor afirma que Freud antecipa, sem se dar conta disso, as pesquisas de Saussure e do Círculo de Praga. Poderia explicar-se a esse respeito?" (LACAN, 1970/2003, p. 400).

Ao responder a essa questão, Lacan articula duas máximas:

1) "O inconsciente é a condição da linguística" (LACAN, 1970/2003, p. 403).

2) "A linguagem é a condição do inconsciente" (LACAN, 1970/2003, p. 404).

Lacan indica que a linguística, como figura da ciência moderna, teria sido inaugurada por este algoritmo: S/s. Da fórmula, invertida da original de Saussure por Lacan, é destacada a barra colocada entre o significante e o conceito a que ele vem se referir. Ora, é pela incidência desse corte (dessa barra) que a linguagem é autonomizada de sua relação ao referente, ao qual ela pode, contingencialmente, vir a demarcar com sucesso. Passando por debaixo da barra, o significado vê desfilar, logo acima, o significante com toda a sua primazia. O significado não é um índice fracionado dos termos de um signo unitário, mas o efeito do encadeamento de um significante ao outro na cadeia simbólica. Desse modo, o sentido captável de uma articulação da cadeia de linguagem passa a depender não do rigor de um conceito atributivo, mas do efeito de retroação de um S2 a um S1, numa linha diacrônica de significação.

Esse fato, demonstrado rigorosamente pela linguística de Saussure e do Círculo de Praga, implica, segundo Lacan, uma "exclusão metafísica, a ser tomada como fato de des-ser" (LACAN, 1970/2003, p. 401). Aí, nenhuma significação poderá ser mais "tida como evidente". A linguística autonomiza os jogos intrínsecos à linguagem. Diferente da esperada conaturalidade do conceito ao referente - não é à toa que Lacan evoca este curioso diálogo de Platão (2001), o Crátilo -, ela destaca as operações da linguagem, independentes do 
ser das coisas por ela referidos. Esse movimento indica precisamente o fato do des-ser, ou seja, o afastamento progressivo da preocupação com a ontologia que, desde a organização da estrutura do logos pela filosofia ocidental, implica uma relação direta a seu fundamento discursivo.

Mas, o que dizer dessa antecipação de Freud à linguística, indicada na questão? O que Freud (1901/1996) revela, desde o início, são os constantes tropeços da fala, expressos pelos chistes, atos falhos e sonhos, disseminados não apenas entre seus neuróticos, mas entre todos aqueles que vivem a banalidade da vida. Esses atos revelam, sob sua pena acurada, todo o império inconsciente subterrado que, mesmo debaixo de escombros, continua a espalhar os efeitos de seu reinado pela história do sujeito. Destacando a importância dos mecanismos de condensação e deslocamento, revelados pelos atos do inconsciente, Freud (1900/1996) demonstra como as palavras operam em nós independentemente de nós mesmos, autonomamente à nossa volição consciente. E mais: a questão do referente é anulada, já que a linguagem, ao invés de revelar a essência das coisas ou dos acontecimentos, tais como eles são ou se dão a nós, escamoteia-os em múltiplos jogos de significação.

Freud (1915/1996) confere, pois, à linguística seu principal substrato ao isolar os mecanismos linguísticos que compõem o inconsciente. Trata-se, enfim, da operação autônoma e inconsciente da linguagem que age segundo leis determinadas e à revelia do sujeito. Ainda que ele afirme que essas leis não respeitam à lógica da não-contradição (princípio determinante, desde Parmênides, para a correção dos enunciados verdadeiros), ainda assim ele destaca, pela constatação dos mecanismos de funcionamento do inconsciente, estruturas que organizam e determinam o funcionamento da linguagem.

Nesse sentido, Lacan justifica a máxima apresentada: o inconsciente - o de Freud - é a condição da linguística ${ }^{1}$. É por destacar essa independência dos significantes em relação às significações que o inconsciente freudiano marca a possibilidade de uma ciência que se desdobre sobre as leis de funcionamento desta estrutura autônoma que é a da linguagem.

Já a segunda afirmação - "a linguagem é condição do inconsciente" destaca algo que Lacan (1956; 1957; 1960; 1964/1998) sempre insistiu em dizer, ainda que não tenha se detido nisso mais demoradamente nesta rádio-transmissão. Se ele o retoma, é com uma função precisa: contestar a inversão laplancheana (LAPLANCHE; LECLAIRE, [1961] 1992) de sua asseveração. Afinal, o inconsciente é o Outro! - quer isso dizer que sua organização é linguajeira; que sem a estrutura da linguagem, presente e disseminada na cultura, qualquer que seja ela, não haveria possibilidade de existência do sujeito e, por simultaneidade, do inconsciente enquanto tal. 
2- "A linguística, a psicanálise e a etnologia têm em comum a noção de estrutura; a partir dessa noção, não será possível imaginar o enunciado de um campo comum que um dia reúna a psicanálise, a etnologia e a linguística?" (LACAN, 1970/2003, p. 405).

Sabemos, de antemão, a negativa sonora que Lacan expressaria diante desta síntese impossível entre campos tão diversos. Mas, coisa estranha, se é justamente por intermédio da linguística de Roman Jakobson e da antropologia de Claude Lévi-Strauss que Lacan constrói sua leitura supra-assumida (Aufhebung) dos textos de Freud, por que então ele precisa distanciar-se de uma e de outra? Ao importar o conceito de estrutura derivado desses dois campos do saber, porque ele não se contenta em propor uma unificação transdisciplinar que incluiria a psicanálise como mais um elemento desse conjunto?

Para Lacan, "a linguística deixa em branco o que surte efeito no inconsciente: o objeto a", objeto pivô do ato próprio à nossa práxis: o dito ato analítico (LACAN, 1970/2003,407). Não é pouco o que Lacan diz nessas breves palavras. Ao situar o lugar do objeto a na estrutura, ele se distancia da estrutura que fora articulada pelo estruturalismo linguístico. Ainda que os elementos dos discursos, tal como formalizados por Lacan (1969-1970/1992), mantenham-se encadeados numa organização precisa, respeitando uma ordem homogênea na sua distribuição em cadeia - (S1, S2, a, \$) - ele confere a essa "nova"2 estrutura características típicas. Primeiro, porque esses elementos podem girar, ocupando cada um, a cada quarto de giro, um lugar específico. A circulação pelos postos cria a possibilidade de cada um dos quatro discursos. Segundo, porque a adição do objeto - nunca feita sem pressupor um sujeito -, clarifica a distância da psicanálise ao estruturalismo: a estrutura é não-toda moldada pela ação do significante, isto é, ela é não-toda linguagem.

Importante destacar o lugar ocupado pelo objeto a neste circuito estrutural. O pequeno objeto vazio esburaca a completude da estrutura simbólica. Lá onde um significante a menos, o "Menos-Um" (LACAN, 1970/2003, p. 407), aciona, por sua exclusão, o campo de funcionamento do Outro, é exatamente lá, nessa subtração, que esse "pequenino" objeto vem se inserir, como um resíduo. É nas fendas do corpo, quase integralmente simbolizado, como Lacan (1964/2008) nos mostra no Seminário 11, que o objeto a cava o seu furo. Alojá-lo no buraco, nas bordas da necessária incompletude do Outro, tem por consequência fazer alastrar na ordem simbólica, na pretensa absolutez da estrutura, o desejo e o gozo ${ }^{3}$.

"Não é menor a barreira da etnologia" (LACAN, 1970/2003, p. 408) - afirma Lacan. 


\begin{abstract}
A partir de uma psicanálise, em si mesma, não se espere recensear os mitos que condicionam o sujeito, pelo fato de ele haver crescido em Togo ou no Paraguai. Pois, como a psicanálise opera a partir do discurso que a condiciona, não obteremos nenhum outro mito senão o que persiste em seu discurso: o Édipo freudiano (LACAN, 1970/2003, p. 409).
\end{abstract}

Temos, portanto, a expressão de uma diferença cabal. Para o antropólogo das Estruturas elementares do parentesco, não são os homens que pensam os mitos, mas, pelo contrário, os mitos, sozinhos, se pensam nos homens. Lévi-Strauss (1971) abstrai de todo sujeito para mostrar como os mitos se articulam entre si; a operação subtrativa por ele realizada tem como consequência varrer qualquer subjetivismo do campo da estrutura. Lacan pensa de modo distinto: o Édipo, esse único mito concebido pela modernidade, revela justamente como a estrutura engendra um sujeito. Ao marcar uma estúpida e inefável existência com a barra de um não ao desejo da Mãe ${ }^{4}$, o assentimento ao Nome-do-Pai faz com que um sujeito, então, advenha. O sujeito está desde sempre relacionado ao Outro, pois é apenas no Outro que ele existe. Ao ser marcado pelo significante, ele surge articulado à estrutura, ao mesmo tempo em que a descompleta. Afinal, um desejo inerradicável é produzido a partir da incisão radical da barra.

Portanto, se é verdade que a etnologia contribui ao mostrar para o psicanalista a existência de uma estrutura transcendente; se a partir disso os mitos podem ser decompostos em unidades simples que denotam, feita uma análise cuidadosa, a universalidade dessa estrutura - não obstante a complexidade fenomênica das formas de aparecimento dos mitos espalhadas pelas culturas antigas -, não se pode dizer, contudo, que a psicanálise encontre aí suas estratégias de intervenção. "Pois não é pelo jogo de mitemas apologéticos, propagados pelos Institutos, que um psicanalista jamais fará uma interpretação" (LACAN, 1970/2003, p. 409).

Uma vez apresentado o mito universal do Édipo, drama aplicável a todos, o que está em causa para a psicanálise é a forma estritamente singular de posicionamento do sujeito frente ao complexo. As saídas, ainda que possam ser descritas em classes - neurose, psicose e perversão -, só se constituem enquanto "classes paradoxais" (MILNER, 2006), ou seja, trata-se sempre de demarcar a maneira própria (histérica, obsessiva ou psicótica) que cada sujeito tem de ser inclassificável. $O$ jeito próprio que o sujeito tem de responder frente ao desejo do Outro, diante do qual não há uma resposta universal, adequada, perfeitamente classificável. Ao tomar nossa práxis como referência, encontramos sempre um sujeito completamente único que frustra a universalidade esperada no Outro. 
"A análise mítica de Lévi-Strauss rejeita tudo o que tenho promovido da instância da letra no inconsciente. (...) Ele [o mito] não condensa, explica. Não desloca, aloja" (LACAN, 1970/2003, p. 410) - afirma Lacan. A evidência encontrada é esta: Lévi-Strauss, guiado pelo ideal da ciência, faz uma verdadeira assepsia do sujeito e entrega-nos uma estrutura completa. Lacan, por uma torção topológica, faz o sujeito participar da estrutura, ao mesmo tempo em que a fura, ao inserir nela este objeto, o pequeno $a$.

3- "Não seria uma das articulações possíveis entre o psicanalista e a linguística o privilégio conferido à metáfora e à metonímia, para Jakobson, no plano linguístico, e pelo senhor, no plano psicanalítico?" (LACAN, 1970/2003, p. 413).

Essa pergunta segue a anterior. O entrevistador força o paralelo entre o estruturalismo linguístico e psicanalítico, tendo agora como alvo não mais o topos da estrutura, mas o lugar de destaque ocupado pelas figuras de linguagem - metáfora e metonímia - presentes tanto nos textos de Jakobson quanto nos de Lacan.

Pela lente lacaniana, a metáfora e a metonímia, descritas por Jakobson, podem assim ser articuladas: "substituição de um significante por outro, numa, e seleção de um significante em sua sequência, na outra." Isso resulta, para o linguista do Círculo de Praga, "que a substituição é feita de semelhança, e a seleção de contiguidade" (LACAN, 1970/2003, p. 413).

Se assim é para a linguística, para a psicanálise, desde as descobertas de Freud, as coisas se passam diferentemente. A metáfora não é a condensação, apesar de ser evidente que ela é um mecanismo que, "operando a serviço do recalcamento" (LACAN, $1970 / 2003$, p. 415), pode produzir a estrutura condensada de um sintoma neurótico. Como efeito da consideração produzida, dizer que "o inconsciente é estruturado como uma linguagem" não significa, em absoluto, afirmar uma relação de identidade entre termos. O inconsciente não é uma linguagem, ele é apenas organizado por e estruturado como. As leis que nele vigoram obedecem a alguns determinantes dinâmicos que lhe são inerentes.

A metáfora, embora seja um mecanismo que auxilia na elucidação da estrutura do sintoma, em nada serviria à psicanálise caso nossa opção fosse abandonar as causas que determinam seus modos de organização, habitualmente tão diversos, nos sujeitos. 0 rastreamento do efeito de condensação demonstra a variedade de significações que, a partir do recalque, um sujeito pode produzir. No final da análise, uma vez percorrido o longo percurso de sentidos condensados, o que se vê é "o reaparecimento do impossível, o ser concebido como limite pelo qual se instaura, através do simbólico, a categoria do real." (LACAN, 1970/2003, p. 415). O encontro com o 
real, destino do processo psicanalítico, é o inverso daquilo que a linguística guarda como seu fundamento. Para esta última, tudo é simbólico. O que não é - como os anagramas da poesia saturniana encontrados por Saussure -, não deve ser publicado, isto é, deve ser varrido de sua consideração.

Em relação à metonímia, "não é pelo sentido de antes do sujeito que ela funciona, mas pelo gozo em que o sujeito se produz como corte." (LACAN, 1970/2003, p. 416). O desejo se apresenta por um mecanismo metonímico. Ele não cessa seu desfile pela cadeia contínua de significantes que o demarcam, visto que o lugar de sua sustentação é o que é dado pela falta. Porém, a referência de Lacan ao gozo demarca a ausência de pureza do desejo. Ainda que este não encontre seu termo em nenhum dos objetos empíricos dispostos na realidade, sua causa é atribuída a um objeto distinto: o pequeno a. Duas coisas devem, então, ser assinaladas: de um lado, o desejo é estruturado como uma longa - quase infinita - cadeia metonímica. Ele circula entre significantes sem encontrar, em nenhum deles, a plenitude de sua realização. Por outro lado, a falta que o sustenta recebe sua materialidade do objeto que o causa; esse objeto é, para o sujeito, aquilo que o faz gozar.

Quando um analista corta uma longa cadeia discursiva, dois efeitos podem ser produzidos no analisante: o primeiro refere-se ao aparecimento de um desejo que interrompe a continuidade monótona do discurso; o segundo revela o lugar, que exige longo tempo para ser demarcado, onde o desejo encontra, enfim, o gozo. Afinal, ainda que sejam múltiplos os dialetos do desejo, geralmente ele repete, sempre e incessantemente, uma mesma frase.

Por fim, Lacan destaca que é conveniente

\begin{abstract}
dizer que o desejo de ser o mestre contradiz o fato mesmo do psicanalista: é que a causa do desejo distingue-se de seu objeto. O que a metonímia dos linguistas atesta está ao alcance de outros que não o psicanalista.

Do poeta, por exemplo, que, no pretenso realismo, faz da prosa o seu instrumento (LACAN, 1970/2003, p. 417).
\end{abstract}

Para o psicanalista é preciso, pois, passar do fato linguístico delimitado pelo linguista e que implica a foraclusão do sujeito do campo de circunscrição da sua ciência - ao sintoma. Somente ao escutar o sintoma das histéricas, rechaçado pela psiquiatria de sua época, que Freud pôde dar origem à psicanálise. Somente deslocando a mestria discursiva da ciência - sobretudo das ciências médicas - é que podemos sustentar continuamente a aposta em nossa prática.

4- "O senhor diz que a descoberta do inconsciente levou a uma segunda revolução copernicana. Em que o inconsciente é uma 
ideia-chave que subverte toda a teoria do conhecimento?" (LACAN, 1970/2003, p. 418).

Lacan inicia seu comentário com uma retificação da pergunta. Seguindo as considerações de Alexander Koyré (1982), ele afirma que a revolução em causa não foi promulgada por Copérnico, assim como havia destacado Freud, mas por Kepler. Copérnico, ao deslocar o centro do Universo da Terra para o Sol, o faz sem se afastar demasiadamente da astronomia ptolomaica. Ainda que os orbes planetários não tenham mais suas trajetórias reguladas pelo centro da Terra, o movimento perfeito em torno do astro-rei continua a ser predominante: trata-se da continuidade da perfeição imaginária da esfera que, por sua função, mantém o sujeito-observador no centro da observação (LACAN 1960-61/1992).

Para Lacan, o destaque dado por Freud à revolução astronômica copernicana, se não é tão correto, ao menos "serve de metáfora apropriada para além daquilo pelo qual Freud a comenta" (LACAN, 1970/2003, p. 420). Lacan a toma de volta porque, a partir da historiografia de Koyré, ele pode corrigi-la para dar-lhe outra dimensão. Foi Kepler quem genuinamente subverteu a astronomia antiga, ao retirar do universo a circularidade perfeita que lhe era atribuída. Ao se atirar, com uma disciplina memorável, à observação dos corpos celestes, ao analisar rigorosamente suas dinâmicas, ele pôde corrigir as imprecisões de Ptolomeu e Copérnico e atribuir ao sistema seu verdadeiro movimento. A teoria kepleriana propõe uma derrisão da esfera, substituindo a pura beleza do círculo pela imperfeição da elipse. O movimento elíptico, para ser constituído e percorrido, necessita de dois focos: no caso do nosso sistema, mantém-se o "luminar mestre" (o Sol) como um deles, mas este conserva uma relação com um "foco desocupado" (LACAN, $1970 / 2003$, p. 420), que não possui uma localização precisa. O que está em causa nessa subversão é a substituição do monocentrismo imaginário, forma limitada do universo finito e impreciso do mundo antigo, por um universo infinito, mas preciso, inscrito em caracteres matemáticos ${ }^{5}$.

A segunda revolução, esta mesma que Freud atribui à sua descoberta, implica, como a primeira, a queda da "soberba ligada a todo monocentrismo" (LACAN, 1970/2003, p. 419). O inconsciente é um achado subversivo porque ele revela, em conflito direto com a psicologia, que o sujeito não é idêntico ao ser que ele supõe ser o seu. A proclamada consciência-de-si, que desde Sócrates se rende ao imperativo oracular - "Conhece-te a ti mesmo!" -, cede seu lugar a este Isso. O sujeito é, então, destronado de sua própria morada, pois algo nele funciona sem que, no entanto, ele saiba dar razões às causas desse funcionamento. Ele é antes agido pelo poder das forças inconscientes do que o agente consciencioso de todas as decisões 
tomadas. Mas - pode-se perguntar -, Freud não age exatamente como Copérnico, ao retirar a centralidade da consciência e atribuí-la ao inconsciente?

Se houvesse ocorrido de fato uma mera substituição da consciência pelo inconsciente, isso resultaria numa concepção de sujeito cuja órbita permaneceria fixada em torno de um centro único - logo, teríamos novamente a referência ao monocentrismo. É por ser obrigatoriamente elíptica que a noção de inconsciente introduzida por Freud possui o qualificativo de subversiva. Vejamos o que diz Lacan:

Foi Freud quem nos revelou a incidência de um saber tal que, ao se subtrair à consciência, nem por isso deixa de se denotar estruturado, digo eu, como uma linguagem; mas, articulado a partir de onde? Talvez de parte alguma em que seja articulável, já que é apenas de um ponto de falta, impensável de outra maneira que não através dos efeitos pelos quais é marcado, e que torna precário que alguém entenda dele, o sentido em que entender do assunto é ser cúmplice de uma natureza em que o ponto de falta nasce ao mesmo tempo que ela: porque aqui, trata-se de uma desnaturação, que torna falso, por outro lado, que alguém se reconheça nela, o que implicaria o modo pelo qual a consciência afirma um saber que é se sabendo (LACAN, 1970/2003, p. 423).

Ora, tal articulação precisa a ordem estrita da relação analógica com a obra de Kepler. O inconsciente é estruturado como uma linguagem (LACAN, [1970] 2003), isto é, seu funcionamento, longe de ser caótico, segue determinadas leis que podem ser apreendidas no caráter universal da estrutura. Temos, logo, este "luminar mestre" a linguagem - que nos permite vislumbrar como o Isso opera em cada sujeito, ou seja, como o gozo deixa-se ser organizado pela linguagem. Porém, onde se situa o ponto de articulação do Isso? Em outras palavras: ao percorrer toda a cadeia de linguagem que estrutura 0 inconsciente, onde um analisante vai parar? Ele vai transformar tudo o que outrora era latente em um conteúdo manifesto absolutamente cristalino? Lacan tenta demonstrar, no texto freudiano, os pontos exatos de inabsorção do inconsciente pela consciência. Do sintoma, da análise dos sonhos, das explicações mais contundentes, resta algo sempre inassimilável à ordem do saber constituído. Através dos efeitos, uma lógica pode ser construída. Ainda que o contato com o "foco desocupado" não seja articulável pela linguagem, existe, contudo, um núcleo deslocado, figura do impossível de descrever e de capturar que, a partir dela, dos seus efeitos, pode ser revelado: o Real. Refazemos, portanto, a geometria da elipse: quebra do monocentrismo e, principalmente, revelação de um foco vazio, inerradicável. 
5 - "Quais são as consequências disso no plano:
a) da ciência;
b) da filosofia; e,
c) mais particularmente, do marxismo, ou até do comunismo?" (LACAN, 1970/2003, p. 432).

Quais as consequências da subversão freudiana para a ciência, a filosofia e o marxismo? O inconsciente implica alguma mudança nesses diversos planos discursivos? Enfim, qual a ação de sua descoberta nesses distintos campos?

Lacan não se esquiva de responder à questão, mas, se o faz, não é sem frustrar as expectativas de sua audiência. $O$ inconsciente - isso que somente é - é, antes, uma descoberta subversiva do que revolucionária. A partir de seu aparecimento no universo do saber moderno, pode-se dizer, sem perigo de equívoco, nenhuma alteração radical no laço social foi agenciada. A psicanálise não pôde ser prescrita como um remédio suficiente para o necessário restabelecimento da saúde dos planos discursivos destacados: a ciência, a filosofia e o marxismo.

A ciência não tocou o ideário Iluminista: seu rápido e contínuo progresso não foi suficiente para que a suposta potência humana se desenvolvesse até atingir o limiar de sua harmonia e perfeição. A filosofia, tragada pelo mundo moderno, tornou-se um discurso marginal, feito apenas para iniciados, incapaz de influenciar, pela trama portentosa de suas cadeias de razão, a vida prática do homem. O marxismo, incorporado por uma série de trágicas revoluções, pôde apenas ver sua teleologia dispersada pelas formas concretas de sua assunção: a queda do poder combatido fez, dos proletários, autocratas ainda mais poderosos.

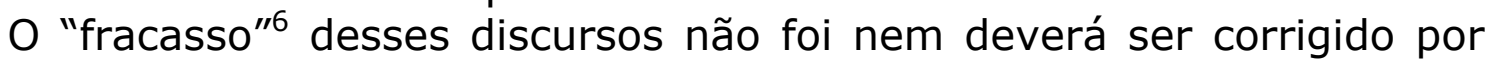
uma psicanálise. O poder da psicanálise não está em atuar sobre eles, no sentido de retificá-los ou aprimorá-los, nem de se insurgir, vestida de camisa vermelha, contra seus equívocos, a fim de se apresentar como uma substituta mais efetiva para a constituição propícia de um "bom" laço social.

Freud, ao atribuir à psicanálise sua função subversiva, faz ver, muito aquém de uma revolução do liame comunitário, uma atuação que só tem sua efetividade se aplicada ao drama do sujeito, contado, sempre, um-a-um. A psicanálise não é uma 'Weltanschauung' (FREUD, 1933/1996) - uma visão de mundo pela qual, uma vez nela iniciados, poderíamos melhor responder todas as questões que a civilização nos propõe. O contexto de seu surgimento, bem como a estruturação de sua prática interventiva, delimita o campo de sua aplicação.

Entretanto, a especificidade da psicanálise, a restrição de sua intervenção, não implica que ela adstrinja suas análises somente ao 
campo subjetivo. Sujeito e cultura andam, como Freud (1921/1996) e Lacan (1968-1969/2008) não cansaram de mostrar, em um processo de pertencimento mútuo: não existiria, bem sabemos, sujeito sem referência ao campo do Outro; a estrutura não funcionaria se estivesse desarticulada dos elementos de sua engrenagem (os sujeitos). Por isso, pode-se dizer que a psicanálise, ao buscar demarcar os impactos da noção de inconsciente para a compreensão do laço social, permite que observemos alguns pontos relevantes da dinâmica interna de seu funcionamento.

Vejamos o que nos diz Lacan:

\begin{abstract}
Ora, certo ou errado, acreditei poder correr o risco de distingui-los [os quatro discursos] do deslizamento - de uma cadeia articulada pelo efeito do significante, considerado como verdade - sobre a estrutura, como função do real na dispersão do saber.

É a partir daí que cabe julgar o que o inconsciente pode subverter. Certamente, nenhum discurso, onde, quando muito, ele aparece por uma enfermidade de fala.

Sua instância dinâmica consiste em provocar a báscula com que um discurso vira outro, por defasagem do lugar onde se produz o efeito do significante.

Seguindo minha topologia feita na enxada, nela encontramos a primeira abordagem freudiana, no sentido em que o efeito de "progresso" a esperar do inconsciente é uma censura (LACAN, 1970/2003, p. 435).
\end{abstract}

Nessa passagem está fortemente afirmado o alcance daquilo que apenas é: o inconsciente. Revelá-lo, como a psicanálise o fez, implica uma subversão do sujeito na dialética profunda de seu desejo. Sua inclusão no mundo moderno, porém, tem como resultado apenas um efeito de báscula. Onde o inconsciente aparece - seja na enfermidade da fala de um paciente, seja na ausência de recobrimento explicativo de uma dada disciplina científica - o que se pode esperar não é o acolhimento e a incorporação, mas a censura. Afinal, sua 'natureza' revela a ordem do excesso de gozo cravado no seio mesmo da cultura. Sua 'natureza' mostra, com toda a força, o inextirpável malestar com que temos, continuamente, que lidar em nossa vida cotidiana.

Ainda que não seja revolucionária, a ponto de produzir uma nova configuração social, a subversão psicanalítica tem, sim, consequências para o campo dos discursos enumerados, pois, a partir do inconsciente, o pensamento sobre a causa e os efeitos que ela engendra é densamente modificado.

A articulação do objeto a como o resíduo ineliminável das operações da estrutura vem indicar que o menos-de-gozo daí resultante tende a retornar nas tentativas desesperadas de supri-lo de qualquer modo. Portanto, a subtração original cria o excesso do mais-de-gozar, 
expresso pelo imperativo super-egóico - 'Goze mais, quem sabe algum dia você chega lá?'

Foi a partir de Marx, da sua noção de mais-valia, que Lacan (19681969/2008) cunhou o mais-de-gozar. Marx aponta, com uma precisão louvável, como a engrenagem do capital, ao incluir o excesso na ordem de seu funcionamento, impulsiona a máquina a trabalhar cada vez mais intensamente. Lacan, sempre atento ao excedente, relaciona-o ao gozo, fazendo ver que a estrutura do capitalismo obtém seu sucesso porque incide, justamente, na constituição arcaica do sujeito. Vejamos o que ele diz:

A mais-valia é a causa do desejo do qual uma economia faz seu princípio: o da produção extensiva, portanto insaciável, da falta-de-gozar. Esta se acumula, por um lado, para aumentar os meios dessa produção como capital. Por outro lado, amplia o consumo, sem o qual essa produção seria inútil, justamente por sua inépcia para proporcionar um gozo com que possa tornar-se mais lenta (LACAN, 1970/2003, p. 434).

Logo, o que a produção incessante de objetos visa, não é à supressão das necessidades do consumidor. Pelo contrário, ao atuar sobre o desejo, os contínuos novos produtos criam novas "necessidades", deixando os consumidores constantemente em falta em relação às renovadas tecnologias de mercado. A falta-de-gozar tende a ampliar o consumo - visto ser ela o motor do consumismo - e, por conseguinte, gerar o capital excedente imprescindível para aumentar, ainda mais, o número de objetos ('gadgets') que, num círculo vicioso, tendem a revigorá-la.

O que Lacan faz, a partir da teoria dos discursos, é restabelecer o lugar do sujeito do inconsciente nessa complexa economia de mercado. A dialética instituída entre o burguês e o proletário, entre 0 senhor e o escravo, é regulada pelo gozo: gozo do explorador, que quer proteger "sua participação patente na sede da falta-gozar" (LACAN, 1970/2003, p. 435); gozo do explorado que, frente ao perigo do não-reconhecimento pelo senhor, aliena-se aos seus imperativos e goza com o desejo de um dia participar - por suas posses, pela conquista do direito de consumo - do posto ocupado por seu amo, conforme Lacan (1960/1998, p. 825) esclarece no texto Subversão do sujeito e dialética do desejo no inconsciente freudiano. Ao falar da ciência, Lacan nos reenvia a Sócrates. Sócrates, ao andar pela pólis, ao dialogar com seus interlocutores, frequentemente os coloca em dúvida sobre o conhecimento que eles supostamente possuem, visto que são reconhecidos, em toda a cidade, por portá-lo. Por um intenso jogo maiêutico, o filósofo descobre o abismo que separa a 'doxa' sofística da 'episteme'. Apesar da histeria de Sócrates, que o impedia de alcançar um conhecimento verdadeiro 
(afinal, ele só soube que nada sabia), foi ele quem abriu as portas para a fundação da ciência.

Lacan detecta nesse fato um sutil paradoxo: como pôde a ciência ganhar impulso a partir do discurso histérico, visto que quem ocupa o lugar de agente, aí, é o sujeito dividido? Se a ciência é o resultado de uma "ideologia da supressão do sujeito" (LACAN, 1970/2003, p. 436), como pode o sujeito ocupar o posto de agente do discurso?

A histérica é aquela que coloca o Mestre contra o muro, indicando que, se ele sabe, seu saber é exclusivamente parcial: ele não dá conta, sobretudo, de responder à pergunta essencial sobre a relação entre os sexos. O saber do mestre é incapaz de dizer à histérica algo sobre o seu verdadeiro desejo. Por correspondência, a alusão a Sócrates revela isto: as aporias que resultam dos seus diálogos apontam para a impotência dos reconhecidos mestres atenienses em sustentar a verdade de seus ditos. Convoca-os, a partir daí, a retificar a ordem de seus discursos. Também a ciência, frequentemente, depara-se com um fato semelhante: ela tem, segundo Popper (1992), que construir hipóteses que sejam refutáveis, ou seja, seus enunciados devem passar, constantemente, pelo crivo da dúvida. Ora, desde Descartes (1637/1999) temos visto que a dúvida é o índice, ainda que borrado, da divisão do sujeito (LACAN, 1964/1998). Desse modo, se de uma perspectiva o discurso da histérica revela 0 inconsciente em pleno exercício, impulsionando a ciência; de outra, a ciência tende a desconhecer essa função. Porém, não se trata somente de desconhecimento, mas de uma completa supressão do sujeito dos seus métodos e procedimentos; fato reforçado na modernidade pela burocracia agenciada na figura do Universitário (LACAN, 1969-1970/1992).

O interesse subversivo da psicanálise é, segundo indica Lacan, "produzir o saber pelo qual se determina a causa que é um desafio em seu ente." (LACAN, 1970/2003, p. 438). Portanto, o empreendimento a que se lança o psicanalista é o de escrever a causa e não ignorá-la e nem, diante dela, calar-se.

6- "Em que o saber e a verdade são incompatíveis?" (LACAN, 1970/2003, p. 440).

Essa indagação não é, de modo algum, fácil de ser respondida. Afinal, quando se coloca para um psicanalista a questão da verdade, é uma categoria negativa que está em jogo. Não existe complementaridade entre saber e verdade: as duas categorias são incapazes de compor um todo. O todo é, para Lacan, o índice do conhecimento e não a marca do saber (LACAN, 1970/2003, p. 440). A distinção é importante, pois demarca duas formas disjuntas de operação sobre o real: uma própria à filosofia e, a outra, específica da ciência moderna. 
O filósofo busca, ao desenhar seus complexos sistemas fechados, determinar o sentido último do Todo. Seus sistemas explicativos, geralmente bem articulados, têm como alvo o estabelecimento do sentido do sentido, ou seja, a delimitação da origem e da finalidade de toda a criação. A busca empreendida é, então, a de capturar todo Real pelas cadeias da razão, isto é, formular uma linguagem universal que balize a compreensão integral da verdade.

Já a categoria "saber" refere-se à ciência - na acepção moderna do termo. A ciência, ao reduzir as relações observadas na natureza a pequenas fórmulas matemáticas, retira de suas considerações a referência ao sentido. Sua preocupação é, antes, demonstrar como se articulam tais relações e não determinar porque elas estão articuladas deste ou daquele modo. A ciência produz um verdadeiro esvaziamento do excesso Imaginário da significação do mundo para, a partir do Simbólico - das pequenas letrinhas - poder explicar o Universo e operar sobre ele. O Real surge, para o cientista, como uma categoria impossível; afinal, como ele pode encontrar efetivamente na natureza a ordem numérica que, pelos mecanismos inerentes à sua razão, ele foi capaz de criar? Como ele pode predizer todo o futuro se, na engrenagem infinita do tempo, podem existir relações que a finitude de suas observações não poderá jamais alcançar? (KOYRÉ, 1982). Segundo Popper (1992), as hipóteses da ciência só ganham o qualificativo de científicas se puderem ser refutadas; em outras palavras, se puderem passar pela prova frequente da dúvida e das novas e sucessivas experimentações. Os enunciados científicos devem criar as condições de possibilidade para sua própria falsificação, com o objetivo preciso de permitir que novos saberes - saberes progressivamente mais verdadeiros - possam, então, se constituir.

A psicanálise, ainda que mantenha o Real como figura do impossível, o faz de modo distinto da ciência. A retomada da questão da causa feita por ela não implica, de modo algum, a absorção completa dessa causa na ordem do saber analítico. Afinal, Lacan não cansa de afirmar: a metalinguagem não existe! A verdade promulgada pela psicanálise não pode ser objeto de amor - como o é para o filósofo visto ser ela justamente o que terrifica quem espera a completude: a única verdade segura é a da castração (LACAN, 1969-1970/1992).

"Da verdade não temos que saber tudo" (LACAN, 1970/2003, p. 442), pois, desde Freud, é essa a pista investigativa que temos: paradoxalmente, somente pelo falso é que podemos seguir seu rastro. Onde a verdade se oculta, é exatamente lá que ela faz seu aparecimento (LACAN, 1956/1998). E, uma vez levados pelo processo da análise, o que podemos encontrar no final é essa irredutibilidade da verdade ao saber, expressa pelas figuras do impossível. Isso não significa que da verdade nada se saiba - se 
assim fosse, dispensaríamos os anos gastos em análise -, mas que ela, se é sabida, é não-toda sabida.

Para dissipar um mal-entendido, Lacan traça uma importante diferença. Diz ele: "o real não é uma verdade, é o limite da verdade" (LACAN, 1970/2003, p. 443). A verdade da castração encontra seu limite na potência negativa do Real. Aqui, a distinção em relação à ciência é profunda, pois a impossibilidade antevista pela psicanálise é a marca da inexistência da "relação sexual". Ora, tal marca, tal impossibilidade de aceder à completude amorosa esperada entre os sexos, sulca profundamente o sujeito. A falta-de-gozo, indicador constitutivo da subjetividade, impulsiona-o para o excesso do maisde-gozar, isto é, para a derrisão mortífera do gozo representada pela busca desesperada de encontrar o que, por estrutura, inexiste. $O$ Real impossível da ciência, esse resíduo permanente da falta de recobrimento da realidade pela via da articulação simbólica, é diferente daquele proposto pela psicanálise. Lacan (1971/2009, p. 27) afirma que "o discurso científico progride sem sequer preocuparse mais em saber se é ou não semblante". Da sexualidade, a ciência nada quer saber: ela foraclui essa causa, só percebendo dela os efeitos revelados pelo impossível de conceber. A psicanálise, num movimento oposto, retorna à causa e denuncia o horror do vazio da falta de proporção entre os sexos que traga, para o seu núcleo, todo sujeito. Demonstra que o real propriamente dito se encarna no gozo sexual como aquilo que é impossível: "não existe ato sexual" (LACAN, 1971/2009, p. 32).

7- "Governar, educar e analisar são três desafios insustentáveis. No entanto, essa contestação perpétua de todo discurso, em especial do dele, é algo a que o psicanalista tem que se agarrar. Ele se agarra a um saber - o saber analítico - o qual contesta por definição. Como o senhor resolve ou não resolve essa contradição? Status do impossível? O impossível é o real?" (LACAN, 1970/2003, p. 443).

Pela análise, não há (...) senão impossibilidade de governar aquilo que não se domina, ao traduzi-la como impossibilidade da sincronia de nossos termos: mandar no saber. Para o inconsciente, isso é a barra.

No tocante à histeria, é a impotência do saber que seu discurso provoca, animando-se no desejo - que revela em que o educar fracassa (LACAN, 1970/2003, p. 445).

Lacan tenta encontrar, nos discursos da histérica e do psicanalista, o álibi que justificaria a insustentabilidade dos dois outros discursos: do Mestre e do Universitário. Isso porque, pela teoria dos discursos, ele pôde formalizar as proposições de Freud (1937/1996) acerca das profissões ditas impossíveis: além da tarefa de analisar, expressa 
pelo Discurso do Analista; o Discurso do Mestre representaria o desafio de governar e o Discurso do Universitário o desafio de educar. A articulação em cadeia que, por um quarto de giro, nos leva de um a outro discurso, bem como a disjunção entre os postos "saber" e "verdade" presentes na própria estrutura discursiva, nos fornecem as pistas para compreender o significado da impossibilidade de cada uma dessas profissões.

"No discurso do mestre - afirma Lacan -, é o mais-de-gozar que só satisfaz o sujeito ao sustentar a realidade unicamente pela fantasia" (LACAN, 1970/2003, p. 445). O governante, ao identificar-se ao significante-mestre que agencia seu discurso, coloca-se como aquele capaz de gerir, com a força inquestionável de sua autoridade, a economia de gozo dos seus governados. Ora, Lacan demonstra a dupla impossibilidade de sua posição: de um lado, o amo só pode gozar por procuração. Seu acesso ao gozo é regulado pelo assujeitamento "voluntário" daqueles que se deixam reger, pois são estes que, com o seu saber e a sua força, fazem a cidade funcionar. De uma forma simples, pode-se dizer que, sem o escravo, o senhor inexiste: o senhor depende do escravo para gozar. Por outro lado, a colagem do governante ao significante-mestre (S1) tende a escamotear a verdade que rege o discurso: o Mestre é castrado $(\$)$, ou seja, ele é, também, um sujeito dividido.

O Discurso do Analista, por ser avesso ao do Mestre, demonstra claramente a impossibilidade do ato de governar: ao se fazer de objeto causa do desejo, o psicanalista lança o sujeito na sua divisão, demonstrando-Ihe isto: que o inconsciente não se deixa dominar. A análise revela, portanto, aquilo que o seu avesso esconde.

Já no Discurso Universitário, a disjunção entre saber e verdade revela "a hiância em que é tragado o sujeito que ele produz, por ter que supor um autor ao saber" (LACAN, 1970/2003, p. 445). Esse é chamado o discurso do mestre-moderno. O saber como agente (S2) discursivo domina nosso tempo. Novas descobertas, novas tecnologias, novos conhecimentos abundam com uma intensidade turbilhante. Essa célere dinâmica tende a produzir um sujeito eclipsado por sua divisão. Ele só conhece a falta, visto ser incapaz de acompanhar a intensa velocidade desse excesso de saber produzido. A suspensão na falta-de-saber lança-o no desafio de encontrar um autor a quem atribuir a magnitude do saber produzido; pois, ele mesmo, é impotente frente a esse lugar.

A impossibilidade de educar é marcada por este fato: ao remeter-se ao saber como um campo autônomo e constituído, a perspectiva do educador é produzir no (a)studante somente sua divisão. Afinal, uma vez que o saber está disponível, o aluno não tem mais o que fazer senão buscá-lo a todo custo. O que fica velado é que a validade do saber encontra-se ancorada no desejo de um professor (ou de um pedagogo), que o aponta ao estudante como verdade. O mestre (S1) 
permanece marcando o caráter arbitrário daquilo que é demandado ao aluno: Saiba mais! Ora, o aluno submete-se ao imperativo na crença de que o currículo que lhe é apontado necessita ser seguido e, se ele não consegue livrar-se de sua falta, é devido a sua própria impotência e não à impossibilidade de saber. Não percebe, entretanto, que colocar a barra da falta do lado do aluno é um fato que determina a própria estrutura da relação pedagógica. Não importa o que faça, sempre estará em falta e deve, por isso, continuar a estudar e a produzir.

O Discurso da Histérica é o avesso do Discurso Universitário, pois a histérica revela, justamente, a impotência do saber frente ao gozo. Ao indagar o Mestre sobre sua divisão, o que ela lhe indica é que ele, em toda a sua imperiosa autossuficiência, é incapaz de oferecer-Ihe uma resposta frente ao enigma de seu desejo. A histérica é, portanto, aquela mesma que propõe que a ausência de resposta para a questão de ouro da psicanálise - o que quer uma mulher? - é, no final das contas, devido à impotência do mestre que lhe responde do lugar do Outro.

Para Lacan, o Discurso do Analista "permite circunscrever o real de que sua impossibilidade exerce a função" (LACAN, 1970/2003, p. 446). Não há aqui, como nos outros discursos, a negação do impossível, que tende, uma vez negado, a retornar com força devastadora. O processo de uma análise leva o sujeito a percorrer sua impotência diante do Outro, até acuá-lo no seu último reduto. Nesse lugar, ele descobre que, no final das contas, o Outro não existe, isto é, não há um lugar de onde alguém poderia suprir a sua falta. Há um impossível que marca a relação dele, sujeito, frente ao seu desejo de ser todo. Ninguém mais poderá respondê-lo, visto que o objeto que ele procura não pode, pela impossibilidade mesma da estrutura, ser encontrado.

\section{Conclusão}

Para concluir, no decorrer das respostas de Lacan às perguntas que Ihe foram formuladas, observamos um duplo movimento, cujo destaque pôde facilitar-nos o acompanhamento de seu raciocínio. Um primeiro movimento é o de situar as especificidades do discurso da psicanálise, entre outros que colocam o homem como objeto, como o da linguística, o da antropologia e o da filosofia. Lacan destaca, então, a especificidade epistemológica que marca a tomada, pela psicanálise, de um sujeito esvaziado de qualquer relação imanente com um saber. A dimensão de ruptura e de subversão posta em causa pela noção de um inconsciente estruturado como uma linguagem também é esclarecida: não se trata de nenhuma revolução capaz de abolir os outros discursos sobre o real, mas de um discurso 
que destaca a hiância que permite a circulação entre os diversos modos discursivos.

Um segundo movimento é o de apresentar as relações entre os outros discursos e o da psicanálise de uma maneira formal ou topológica. Não se trata de nenhuma essência característica de uma visão de mundo psicanalítico, mas de uma forma de operar com o real. Ao formalizar o modo de funcionamento dos diversos discursos a partir do esquema dos quatro discursos, Lacan nos oferece uma ferramenta topológica que esclarece o modo de operação do discurso psicanalítico frente ao real. Não se trata de esconder a impossibilidade de transformar em saber o que é da verdade, como no discurso do mestre. Também não se trata de uma impotência do mestre, como apontaria a histérica, ou de uma impotência do estudante, como apontaria 0 discurso da universidade. A impossibilidade é um fato de estrutura. O discurso da psicanálise é o que destaca a impossibilidade, fazendo com que a falta inerente à estrutura discursiva permita uma circulação entre diferentes modos de se lidar com o real.

\section{Referências}

DESCARTES, R. Discurso do Método; As paixões da Alma; Meditações. Tradução Enrico Corvisieri. São Paulo: Ed. Nova Cultural (Os pensadores), 1999.

FREUD, S. (1900). A interpretação dos sonhos. In: Edição

Standard Brasileira das Obras Psicológicas Completas de Sigmund Freud (ESB). Rio de Janeiro: Imago, 1996. V. 4-5.

FREUD, S. (1901). A psicopatologia da vida cotidiana. In:

ESB. Rio de Janeiro: Imago, 1996. V. 6.

FREUD, S. (1915). O Inconsciente. In: . ESB. Rio de Janeiro: Imago, 1996. v. 14, p. 165-222.

FREUD, S. (1921). Psicologia das massas e análise do ego. In: ESB. Rio de Janeiro: Imago, 1996. v. 18, p. 89-179.

FREUD, S. (1933). Novas conferências introdutórias; conferência XXXV - A questão de uma Weltanschauung. In: . ESB. Rio de Janeiro: Imago, 1996. v. 22, p. 155-177.

FREUD, S. (1937). Análise terminável e interminável. In:

ESB. Rio de Janeiro: Imago, 1996. v. 23, p. 223-270.

KOYRÉ, A. Estudos da história do pensamento científico. Rio de Janeiro: Ed. Forense Universitária; Brasília: Ed. Universidade de Brasília, 1981.

LACAN, J. (1956). A coisa freudiana ou Sentido do retorno a Freud em psicanálise. In: Escritos. Tradução Vera Ribeiro. Rio de Janeiro: Jorge Zahar, 1998. 
LACAN, J. (1957). Instância da letra no inconsciente ou a razão desde Freud. In: Escritos. Tradução Vera Ribeiro. Rio de Janeiro: Jorge Zahar, 1998.

LACAN, J. (1957-1958). O Seminário, livro 5 - as formações do inconsciente. Rio de Janeiro: Jorge Zahar, 1999.

LACAN, J. (1960). Subversão do sujeito e dialética do desejo no inconsciente freudiano. In: . Escritos. Tradução Vera Ribeiro. Rio de Janeiro: Jorge Zahar, 1998.

LACAN, J. (1964). Posição do Inconsciente. In: Escritos. Tradução Vera Ribeiro. Rio de Janeiro: Jorge Zahar, 1998.

LACAN, J. (1960-61). O Seminário, livro 8: a transferência. Rio de Janeiro: Jorge Zahar Editor, 1992.

LACAN, J. (1962-1963). O Seminário, livro 10: a angústia. Rio de Janeiro, Jorge Zahar Editor, 2005.

LACAN, J. (1964). O Seminário, livro 11: os quatro conceitos fundamentais da psicanálise. Rio de Janeiro, Jorge Zahar Editor, 1998.

LACAN, J. (1968-1969). O Seminário, livro 16: de um Outro ao outro. Rio de Janeiro: Jorge Zahar, 2008.

LACAN, J. (1969-1970). O Seminário, livro 17: o avesso da psicanálise. Rio de Janeiro: Jorge Zahar, 1992.

LACAN, J. (1970). Radiofonia. In: Outros Escritos. Rio de Janeiro: Jorge Zahar Ed., 2003.

LAPLANCHE, J.; LECLAIRE, S. (1961). O inconsciente, um estudo psicanalítico. In: LAPLANCHE, J. O I nconsciente e o I d. São Paulo: Martins Fontes, 1992.

LÉVI-STRAUSS, C. Mitológicas: o cru e o cozido. São Paulo: Ed. Brasiliense, 1991.

PLATÃO. Teeteto - Crátilo. Belém: EDUFPA, 2001.

MILNER, J-C. Os nomes indistintos. Rio de Janeiro: Cia de Freud, 2006.

POPPER, K. A lógica da pesquisa científica. São Paulo: Cultrix, 1992.

\section{Endereço para correspondência}

Fábio Santos Bispo

Escola Judicial Desembargador Edésio Fernandes - Tribunal de Justiça do Estado de Minas Gerais - Rua dos Guajajaras, 40 - $19^{\circ}$ andar, CEP 30180-100, Funcionários Belo Horizonte, MG.

Endereço eletrônico: fabio.siloe@gmail.com

Marcelo Fonseca Gomes de Souza

FACED - Praça do Mercado, 191, CEP 35500-048, Divinópolis - MG.

Endereço eletrônico: marcelofgsouza@gmail.com

Recebido em: 01/08/2011

Reformulado em: 16/03/2012

Aceito para publicação em: 13/08/2012

Acompanhamento do processo editorial: Alexandra Cleopatre Tsallis 
Fábio Santos Bispo, Marcelo Fonseca Gomes de Souza

O discurso psicanalítico entre outros: considerações sobre Radiofonia

\begin{abstract}
Notas
* Possui graduação em Psicologia pela Universidade Federal de Minas Gerais (UFMG - 2005), pós-graduação em Psicopedagogia Clínica e Institucional pela Universidade do Estado de Minas Gerais (2007) e mestrado em Psicologia pela UFMG (2010). Atualmente é doutorando do Programa de Pós-graduação em Psicologia da UFMG, na linha de pesquisa Estudos Psicanalíticos. É psicólogo do Núcleo de Desenvolvimento de Competências Humano-Sociais (NUDHS) da Escola Judicial Desembargador Edésio Fernandes (EJEF) do Tribunal de Justiça do Estado de Minas Gerais (TJMG).

** Possui graduação em Psicologia pela Universidade Federal de Minas Gerais (UFMG - 2006) e mestrado em Psicologia pela UFMG (2010). Atualmente é doutorando do Programa de Pós-graduação em Psicologia da UFMG, na linha de pesquisa Estudos Psicanalíticos e professor do curso de Psicologia da Faculdade de Ciências Econômicas, Administrativas e Contábeis de Divinópolis (FACED).

1 Não parece mesmo um tratado de linguística aquele ilustrativo apêndice $C$ (FREUD, 1915/1996), anexado ao final do artigo metapsicológico que tem como tema o Inconsciente?

2 Podemos chamá-la de "nova" por ter sido Lacan quem primeiro a formalizou. No entanto, marcamos nova com aspas, justamente porque essa estrutura, depois de fundada pela escrita de Lacan, significa, por retroação, toda a "velha" história que, por estrutura, herdamos.

${ }^{3}$ Trata-se aqui das duas vertentes do objeto: como causa de desejo (LACAN, 19621963/ 2005) e como mais-de-gozar (LACAN, 1968-1969/2008).

${ }^{4}$ É preciso entender os dois sentidos produzidos pelo não ao desejo da Mãe. Eles podem ser articulados neste duplo imperativo: "Filho, não possuirás tua mãe!". "Mãe, não reintegrarás teu produto!" (LACAN, 1957-1958/1999).

${ }^{5}$ Cabe notar que a concepção do universo infinito aparece já em Galileu. Contudo, Kepler, apesar da sua descoberta, é avesso às formulações galileanas. Para ele, ainda que o universo não seja esférico, ele é limitado. Os planetas, como uma orquestra, reproduziriam uma melodia perfeita. A música do universo só encontraria sua razão na perfeição ilimitada de seu maestro. Trata-se de uma regência impecável feita pela batuta de Deus. Foi preciso Newton para que a síntese entre Galileu, Kepler e Descartes fosse realizável.

${ }^{6}$ É importante colocar o termo entre aspas. Isso grafa que o fracasso é parcial, isto é, ele só é considerado como tal quando o ponto que o legitima como fracassado é exterior a ele. Essa consideração merece destaque principalmente quando consideramos o discurso da ciência. Pois, ao tomá-lo em seu processo contínuo, seu sucesso é, de fato, arrebatador. A ciência realiza seu bem-sucedido empreendimento ao se balizar no que ela capta de essencial no mundo onde ela se aplica: a da massa indiscernível de sujeitos desejantes a quem ela oferece, sem cessar, novos e novos produtos.
\end{abstract}

